\title{
Kajian Termodinamika Adsorpsi Hibrida Merkapto-Silika dari Abu Sekam Padi Terhadap Ion Co(II)
}

\author{
Dwi Rasy Mujiyanti", Noer Komari, Ningtyas Indah Sari \\ Program Studi Kimia Fakultas Matematika dan Ilmu Pengetahuan Alam Universitas Lambung Mangkurat \\ Jln. A. Yani Km. 36 Banjarbaru, Kalimantan Selatan \\ *Email: dwirasy@gmail.com
}

\begin{abstract}
Abstrak
Telah dilakukan penelitian tentang kajian termodinamika adsorpsi hibrida merkapto-silika dari abu sekam padi terhadap ion Co(II). Penelitian ini bertujuan untuk menentukan kapasitas dan energi adsorpsi hibrida merkapto-silika (HMS) dan silika gel (SG) terhadap ion Co(II). Pada penelitian ini, silika gel dibuat menggunakan natrium silikat dari abu sekam padi. Selanjutnya, senyawa organik 3-(trimetoksisilil)-1-propantiol diimobilisasi pada SG menghasilkan HMS. Adsorben dikarakterisasi menggunakan difraktometer sinar-X dan spektrofotometer FTIR. Larutan Co(II) kemudian dikontakkan dengan SG dan HMS pada variasi pH, waktu, dan konsentrasi awal. Hasil penelitian kapasitas adsorpsi yang diperoleh HMS hampir tiga kali lebih besar dibandingkan dengan SG, dengan besarnya kapasitas adsorpsi masing-masing yaitu 250,00 $\mathrm{mg} / \mathrm{g}$ dan 90,91 mg/g. Sedangkan energi adsorpsi yang diperoleh adalah 51,69 KJ/mol untuk SG, dan 23,65 KJ/mol untuk HMS.
\end{abstract}

Kata kunci : sekam padi, hibrida merkapto-silika, adsorpsi, ion Co(II)

\begin{abstract}
A research on the study of the thermodynamics of adsorption mercapto-silica hybrid from rice husk ash to the ions Co (II) has been done. This study aims to determine capacity and energy adsorption of hybrid mercapto-silica (HMS) and silica gel (SG) to the ions Co (II) . In this study, silica gel was made using sodium silicate from rice husk ash. Furthermore, the organic compound 3-(trimethoxysilil )-1-prophantiol immobilized on SG to HMS produced. Adsorbents were characterized using X-ray diffraction and FTIR spectrophotometer. Solution of Co (II) is then contacted with the SG and HMS at the variation of $\mathrm{pH}$, time, and initial concentration. The results obtained by HMS adsorption capacity is almost three times larger than the SG, the magnitude of adsorption capacity of each is $250.00 \mathrm{mg} / \mathrm{g}$ and $90.91 \mathrm{mg} / \mathrm{g}$. While the adsorption energy obtained is $51.69 \mathrm{KJ} / \mathrm{mol}$ for $\mathrm{SG}$, and $23.65 \mathrm{KJ} / \mathrm{mol}$ for HMS.
\end{abstract}

Keywords : rice husk, mercapto-silica hybrid, adsorption, ion $\mathrm{Co}(\mathrm{II})$

\section{PENDAHULUAN}

Logam berat dengan konsentrasi tertentu dalam perairan dapat menjadi sumber racun bagi kehidupan perairan. Berbagai usaha untuk mengurangi kadar logam berat di perairan telah banyak dilakukan. Metode yang paling sering digunakan adalah adsorpsi. Teknik ini lebih menguntungkan daripada teknik yang lain dilihat dari segi biaya yang tidak begitu besar serta tidak adanya efek samping zat beracun (Blais dkk., 2000).

Salah satu padatan anorganik yang banyak digunakan untuk keperluan adsorpsi adalah silika gel karena mempunyai gugus silanol ( $\mathrm{Si}-\mathrm{OH})$ dan siloksan ( $\mathrm{Si}-\mathrm{O}-\mathrm{Si})$. Salah satu sumber silika gel adalah sekam padi.
Nuryono dkk (2004) melaporkan bahwa kandungan silika pada abu sekam padi yang berasal dari Klaten mencapai $98 \%$, sedangkan Mujiyanti dkk., (2010) melaporkan kadar silika dalam abu sekam padi yang berasal dari Gambut mencapai 95,6\%. Kandungan silika yang tinggi ini, menunjukkan bahwa abu sekam padi berpotensi besar sebagai bahan dasar pembuatan adsorben berbasis silika seperti silika gel.

Penggunaan silika gel sebagai adsorben memiliki kelemahan yaitu rendahnya efektivitas apabila digunakan untuk mengadsorpsi ion logam karena interaksi ionion logam dan permukaan silika agak lemah. Hal ini disebabkan oleh sifat keasaman yang 
rendah dari gugus-gugus silanol dan kemampuan mendonorkan elektron yang rendah dari atom oksigen di permukaan. Oleh karena itu, salah satu upaya untuk meningkatkan silika gel dalam mengadsorpsi ion logam adalah dengan mengikatkan senyawa organik yang mengandung gugus fungsional (gugus aktif) seperti: $-\mathrm{CH},-\mathrm{SH}$, dan $-\mathrm{NH} 2$ pada silika gel akan menghasilkan hibrida organosilika (Nuzula, 2004).

Proses sol-gel merupakan salah satu cara memodifikasi permukaan silika secara kimia pada pembuatan material hibrida organosilika. Teknik ini lebih sederhana dan cepat karena reaksi pengikatan berlangsung bersamaan dengan proses terbentuknya padatan. Selain itu, teknik imobilisasi melalui proses sol-gel lebih mudah dilakukan di laboratorium karena reaksi dapat dilakukan pada temperatur kamar sehingga dapat digunakan alat-alat yang lebih sederhana. Pada penelitian ini telah dilakukan modifikasi permukaan silika secara kimia melalui proses sol-gel menggunakan prekursor natrium silika, dengan gugus merkapto dari senyawa 3-(trimetoksisilil)-1-propanatiol. Hibrida organosilika yang dihasilkan akan berinteraksi dengan ion logam.

\section{METODOLOGI PENELITIAN}

\section{Alat dan Bahan}

Alat-alat yang digunakan dalam penelitian ini adalah seperangkat alat gelas dan plastik, spektrofotometer serapan atom (SSA) merk Varian tipe Spectra AA-30, difraktometer sinar-X (XRD) Shimadzu XRD6000, dan spektrofotometer inframerah (FTIR) Shimadzu FTIR Prestige-21, serta peralatan penunjang yang meliputi Furnace Heraceus Hanau ayakan ukuran 170 mesh, Sentrifuge elements GS 150, pengaduk magnet (stirer), oven merk Memmert, timbangan analitik (Mettler AE 160, Jerman), hot plate merk Cimarec, pH meter Jenway 3040 ion Analyzer, cawan porselin, alat penggerus (lumpang dan mortar).

Bahan-bahan yang digunakan dalam penelitian ini adalah sekam padi yang diambil dari daerah Gambut, Kalimantan Selatan sebagai bahan sumber silika, $\mathrm{NaOH} 50 \%$ (p.a Merck), $\mathrm{HCl} 37 \%$ (p.a Merck), 3(trimetoksisilil)-1-propanatiol, $\mathrm{Co}\left(\mathrm{NO}_{3}\right)_{2}$ (p.a Merck), $\mathrm{HNO}_{3}$ pekat (p.a Merck), kertas indikator $\mathrm{pH}$ universal, alumunium foil, kertas saring Whatman no.42, kertas saring biasa, dan akuades.

\section{Preparasi Abu Sekam Padi}

Sekam padi dipanaskan dalam oven pada suhu $190^{\circ} \mathrm{C}$ selama 1 jam. Kemudian dilakukan proses pengabuan di dalam furnace dengan suhu $600^{\circ} \mathrm{C}$ selama $1 \mathrm{jam}$, sehingga dihasilkan abu sekam padi yang dapat digunakan untuk pembuatan larutan natrium silikat.

\section{Pembuatan Natrium Silikat Dari Abu Sekam Padi}

Abu sekam padi hasil pembakaran digerus dan diayak 170 mesh. Abu sekam padi dicuci dengan $\mathrm{HCl} 6 \mathrm{M}$ dan dinetralkan dengan akuades. Abu sekam padi bersih ini dikeringkan dalam oven. Setelah kering, abu sekam padi dilarutkan dengan $\mathrm{NaOH} 4 \mathrm{M}$, dididihkan sambil diaduk dengan pengaduk magnet sampai mengental, selanjutnya larutan dituangkan ke dalam cawan porselin dan dilebur pada temperatur $500^{\circ} \mathrm{C}$ selama 30 menit. Setelah dingin ditambahkan akuades, didiamkan semalam (24 jam), kemudian disaring, dan filtrat yang dihasilkan merupakan larutan natrium silikat $\left(\mathrm{Na}_{2} \mathrm{SiO}_{3}\right)$ yang siap digunakan sebagai bahan pembuatan adsorben silika gel (SG) dan hibrida merkapto-silika (HMS).

\section{Pembuatan Adsorben Silika Gel (SG)}

Larutan natrium silikat hasil dimasukkan ke dalam gelas plastik, ditambahkan $\mathrm{HCl} 3 \mathrm{M}$ secara bertetes-tetes sambil diaduk dengan pengaduk magnet hingga terbentuk gel dan diteruskan hingga larutan netral $(\mathrm{pH} 7)$. Gel yang terbentuk didiamkan semalam (24 jam), dicuci dengan akuades hingga netral yang diamati dengan indikator universal, dan dikeringkan di dalam oven pada temperatur $70^{\circ} \mathrm{C}$. Setelah kering, digerus dan diayak dengan ayakan 170 mesh. Adsorben yang dihasilkan merupakan silika gel (SG).

\section{Pembuatan Adsorben Hibrida Merkapto- silika (HMS)}

Larutan natrium silikat dimasukkan ke dalam gelas plastik, ditambahkan senyawa 3(trimetoksisilil)-1-propanatiol (TMSP). Selanjutnya ditambahkan $\mathrm{HCl} 3 \mathrm{M}$ tetes demi tetes sambil diaduk dengan pengaduk magnet hingga terbentuk gel dan diteruskan hingga larutan netral $(\mathrm{pH}$ 7). Gel yang terbentuk 
didiamkan semalam, dicuci dengan akuades hingga netral yang diamati dengan indikator universal, dan dikeringkan di dalam oven pada temperatur $70^{\circ} \mathrm{C}$. Setelah kering, digerus dan diayak dengan ayakan 170 mesh untuk mendapatkan adsorben hibrida merkapto-silika (HMS).

\section{Karakterisasi Silika Gel dan Hibrida Merkapto-Silika}

Hasil yang diperoleh dikarakterisasi menggunakan spektrofotometer inframerah dan difraktometer sinar-X

\section{Penentuan Kapasitas dan Energi Adsorpsi Ion Co(II) pada Silika Gel dan Hibrida Merkapto-Silika}

Adsorben diinteraksikan dengan larutan Co(II) dengan variasi konsentrasi 20, 40, 80, 100,150 , dan $200 \mathrm{mg} / \mathrm{l}$ pada $\mathrm{pH}$ dan waktu interaksi optimum, kemudian disentrifugasi. Supernatan dianalisis dengan spektrofotometer serapan atom (SSA) untuk menentukan jumlah ion $\mathrm{Co}(\mathrm{II})$ yang tersisa dalam larutan.

\section{HASIL DAN PEMBAHASAN}

\section{Karakterisasi Adsorben Gugus fungsional}

Untuk mengidentifikasi gugus-gugus fungsional yang terdapat dalam silika gel (SG) dan hibrida merkapto-silika (HMS) digunakan spektroskopi inframerah (FTIR). Spektra hasil identifikasi untuk SG dan HMS ditunjukkan pada Gambar 1.

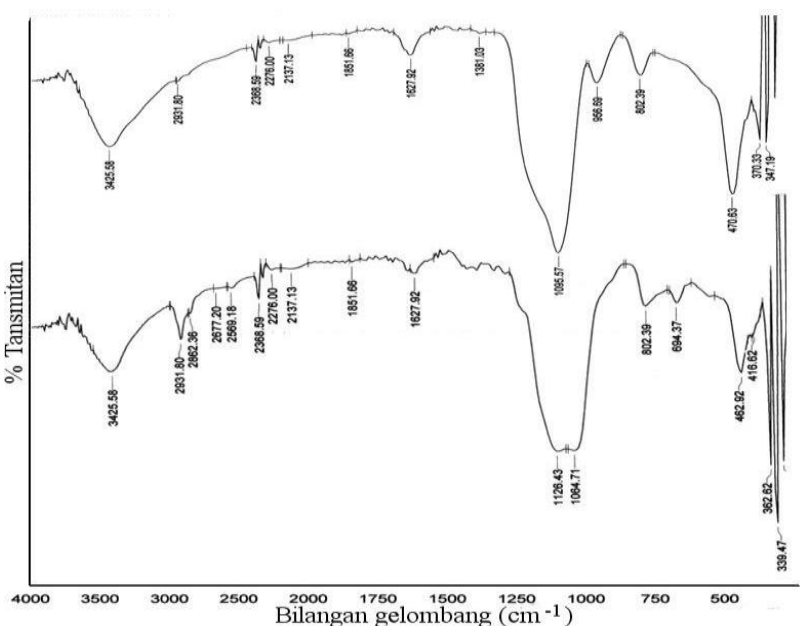

Gambar 1. Spektra serapan FTIR (A) Hibrida Merkapto-Silika, dan (B) Silika Gel dari siloksan pada bilangan gelombang 470,63 $\mathrm{cm}^{-1}$. Vibrasi ulur Si-O dari siloksan ditunjukkan oleh pita serapan pada bilangan gelombang $802,39 \mathrm{~cm}^{-1}$. Vibrasi ulur $\mathrm{Si}-\mathrm{O}$ silanol ditunjukkan oleh serapan pada bilangan gelombang $956,69 \mathrm{~cm}^{-1}$. Pita serapan yang kuat pada bilangan gelombang 1095,57 $\mathrm{cm}^{-1}$ merupakan vibrasi ulur simetris $\mathrm{Si}-\mathrm{O}$ dari siloksan ( $\mathrm{Si}-\mathrm{O}-\mathrm{Si}$ ). Pada bilangan gelombang $1627,9 \mathrm{~cm}^{-1}$ muncul serapan dari vibrasi tekuk -OH silanol, dan pada bilangan gelombang $3425,58 \mathrm{~cm}^{-1}$ muncul serapan dari vibrasi ulur -OH silanol. Secara umum, pita serapan yang muncul pada spektra silika gel menunjukkan bahwa gugus-gugus fungsional yang terdapat pada silika gel hasil pembuatan dari abu sekam padi adalah gugus-gugus silanol $(\mathrm{Si}-\mathrm{OH})$ dan siloksan ( $\mathrm{Si}-\mathrm{O}-\mathrm{Si})$.

Gambar 1 B merupakan spektra dari HMS. Adanya perubahan pola serapan yang terlihat pada spektra yang dihasilkan menunjukkan keberhasilan proses imobilisasi senyawa 3-(trimetoksisilil)-1-propantiol (TMSP) melalui proses sol-gel menghasilkan HMS. Dimana terlihat perbedaan yaitu munculnya serapan dari vibrasi -SH pada bilangan gelombang 2569,18 $\mathrm{cm}^{-1}$ yang munculnya lemah, sesuai dengan Sastrohamidjojo (1992) yang mengatakan bahwa senyawa-senyawa organik yang memiliki gugus -SH menyerap lemah daerah $2600-2550 \mathrm{~cm}^{-1}$. Selain itu muncul pita serapan vibrasi ulur C-S pada bilangan gelombang 694,37. Hilangnya pita serapan pada 956,69 $\mathrm{cm}^{-1}$ yang menunjukkan adanya vibrasi ulur Si$\mathrm{O}$ dari $\mathrm{Si}-\mathrm{OH}$ pada silika gel mengindikasikan berkurangnya jumlah gugus silanol akibat terjadinya kondensasi dengan senyawa TMSP. Perubahan lain yang terlihat adalah pergeseran bilangan gelombang ke daerah bilangan gelombang yang lebih rendah dan perubahan intensitas serapan pada vibrasi tekuk dan ulur simetris $\mathrm{Si}-\mathrm{O}$ siloksan.

\section{Struktur kristal}

Informasi mengenai struktur padatan diberikan oleh difraktogram sinar-X melalui analisis pola difraksi sesuai dengan tingkat kristalinitasnya. Pola difraksi yang dianalisis yaitu silika gel (SG) dan hibrida merkaptosilika (HMS). Beberapa pola difraksi tersebut ditunjukkan pada Gambar 2.

Gambar 1 A merupakan spektra dari silika gel, tampak adanya vibrasi tekuk Si-O 


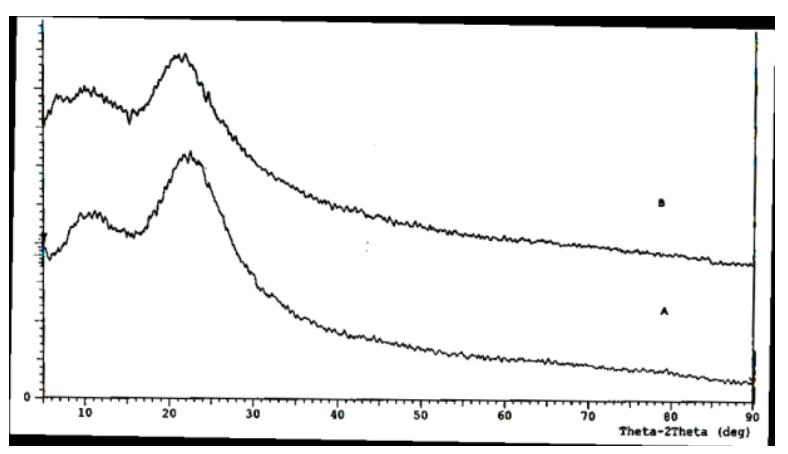

Gambar 2. Difraktogram sinar-X dari (A) Silika Gel, dan (B) Hibrida Merkapto-Silika

Difraktogram silika gel pada Gambar 8 menunjukkan pola yang melebar pada $2 \theta=21$ $23^{\circ}$ dengan intensitas yang maksimum, sedangkan pada difraksi HMS pola yang melebar dengan intensitas yang maksimum ada di sekitar $2 \theta=20-22^{\circ}$. Menurut Kalapathy (2000) silika dengan puncak melebar di sekitar $2 \theta=21-23^{\circ}$ menunjukkan struktur amorf. Dengan demikian, hasil karakterisasi menggunakan XRD menunjukkan SG dan HMS mempunyai struktur amorf bukan kristal.

\section{Penentuan Kapasitas dan Energi Adsorpsi}

Penentuan kapasitas dan energi adsorpsi ion Co(II) pada silika gel dan hibrida merkapto silika ditentukan dengan menggunakan metode pendekatan model isoterm adsorpsi Langmuir.

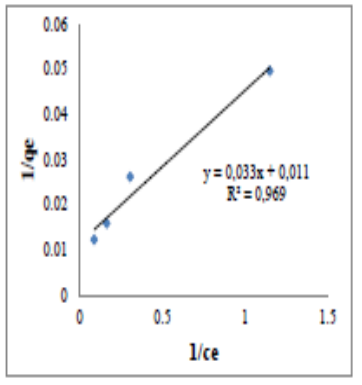

(a)

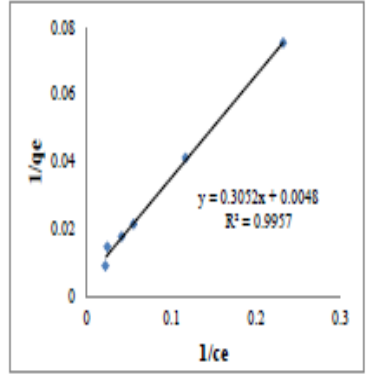

(b)
Gambar 3. Grafik Isoterm Langmuir pada (A) SG, dan (B) HMS

Tabel 1. Parameter Isoterm Adsorpsi Langmuir

\begin{tabular}{ccccc}
\hline Adsorben & $\begin{array}{c}\mathrm{q}_{\mathrm{m}} \\
(\mathrm{mg} / \mathrm{g})\end{array}$ & $\mathrm{K}(\mathrm{L} / \mathrm{mol})$ & $\begin{array}{c}\mathrm{E} \\
(\mathrm{KJ} / \mathrm{mol})\end{array}$ & $\mathrm{R}^{2}$ \\
\hline SG & 90,91 & $330.000,00$ & 51,69 & 0,969 \\
HMS & 250,00 & $13.110,48$ & 23,65 & 0,995 \\
\hline
\end{tabular}

Keterangan :

$\mathrm{q}_{\mathrm{m}}=$ Kapasitas adsorpsi (mg/g)

$\mathrm{K}=$ Konstanta kesetimbangan $(\mathrm{L} / \mathrm{mol})$

$\mathrm{E}=$ Energi adsorpsi

$\mathrm{R}^{2}=$ Kolerasi kelinieran
Kapasitas adsorpsi ion $\mathrm{Co}(\mathrm{II})$ pada hibrida merkapto-silika sebesar 250,00 mg/g, lebih besar dibandingkan dengan silika gel yaitu $90,91 \mathrm{mg} / \mathrm{g}$. Hal tersebut dikarenakan pada adsorben hibrida merkapto silika terdapat situs aktif merkapto (-SH) yang berfungsi sebagai donor pasangan elektron yang berukuran besar dan bermuatan rendah sehingga mudah terpolarisasi. Rendahnya kemampuan atom $\mathrm{O}$ dari silanol dan siloksan dalam mengadsorpsi juga diakibatkan karena atom $\mathrm{O}$ sebagai pendonor berikatan langsung dengan Si dalam struktur silika.

Nilai energi adsorpsi ion Co(II) untuk silika gel sebesar $51,69 \mathrm{KJ} / \mathrm{mol}$, sedangkan energi adsorpsi ion logam Co(II) untuk hibrida merkapto-silika sebesar $23,65 \mathrm{KJ} / \mathrm{mol}$. Nilai energi adsorpsi ini mengindikasikan interaksi antara adsorben dan ion logam terjadi melalui adsorpsi fisik yang melibatkan pembentukan ikatan hidrogen dimana logam berada dalam keadaan terhidrat karena berada dalam media air.

\section{SIMPULAN}

Silika gel dapat mengadsorpsi ion Co(II) secara optimum pada $\mathrm{pH}$, waktu kontak 75 menit, dengan kapasitas adsorpsi sebesar 90,91 $\mathrm{mg} / \mathrm{g}$ dan energi adsorpsi sebesar 51,69 $\mathrm{KJ} / \mathrm{mol}$. Hibrida merkapto-silika dapat mengadsorpsi ion $\mathrm{Co}$ (II) secara optimum pada pH 3, waktu kontak 90 menit, dengan kapasitas adsorpsi sebesar 250,00 $\mathrm{mg} / \mathrm{g}$ dan energi adsorpsi sebesar $23,65 \mathrm{KJ} / \mathrm{mol}$. Silika gel dan hibrida merkapto-silika memiliki struktur amorf dan memiliki gugus fungsional silanol (Si-OH) dan siloksan (Si-O-Si), sedangkan hibrida merkapto-silika juga terdapat gugus merkapto (-SH).

\section{DAFTAR PUSTAKA}

Blais, J.F, Dufresne, B, dan Mercier, G. 2000. State of The Art of Technologies for Metal Removal from Industrial Effluents. Rev, Sci, Eau 12 (4), 687-711.

Komari, N, Junaidi, A.B, dan Fatmawati. 2007. Penggunaan Biomassa Potamogeton Sp Terimobilkan Pada Silika Gel Sebagai Biosorben Cd(II). Sains Kimia dan Terapan, Vol.1, No. 1 (Januari 2007), 41 - 46.

Mujiyanti, D.R, Astuti, M, dan Umaningrum, D. 2010. Pembuatan Silika Amorf dari Limbah Sekam Padi Gambut Kabupaten Banjar 
Kalimantan Selatan. FMIPA-UNLAM, Banjarbaru.

Nuzula, F. 2004. Adsorpsi Cd2+, Ni2+, dan Mg2+ pada 2-Merkapto Benzimidazol yang diimobilisasikan pada Silika Gel. Thesis. FMIPA-UGM, Yogyakarta.

Nuryono, Narsito, dan Astuti, E. 2004. Pengaruh Temperatur Pengabuan Sekam Padi terhadap
Karakter Abu dan Silika Gel Sintetik. Review Kimia, 7(2), 67-81.

Oscik, J. 1982. Adsorption. John Wiley and Sons, New York.

Sastrohamidjojo, H. 1992. Spektroskopi Inframerah, Edisi Kedua. Liberty. Yogyakarta. 